\title{
Stearoyl-CoA desaturase enzyme 1 inhibition reduces glucose utilization for de novo fatty acid synthesis and cell proliferation in 3T3-L1 adipocytes
}

\author{
Jennifer K. Yee, Paulin N. Wahjudi, Juan Vega, Shu Lim, Ashley Martin, Mary E. Patterson, \\ Joshua N. Cohen, Catherine S. Mao, and Wai-Nang P. Lee \\ Department of Pediatrics, Los Angeles Biomedical Research Institute at Harbor-UCLA Medical \\ Center, 1124 West Carson Street, Walter Martin Research Building, Torrance, CA 90502, USA
}

Jennifer K. Yee: jyee@labiomed.org

\begin{abstract}
Stearoyl-CoA desaturase enzyme 1 (SCD1) is a lipogenic enzyme that is upregulated in obesity, insulin resistance, and cancer. Since glucose is a substrate for both de novo fatty acid synthesis and deoxyribose synthesis, we hypothesized that SCD1 affects these multiple synthetic pathways through changes in glucose utilization. This study determined glucose utilization for fatty acid synthesis and cell proliferation in 3T3-L1 preadipocytes during SCD1 inhibition. The effects of SCD1 on cellular metabolism as mediated by its monounstaurated fatty acid products (palmitoleate and oleate) were also observed. 3T3-L1 preadipocytes underwent differentiation induction in conjunction with one of the following treatments for 4 days: (A) no treatment, (B) SCD1 inhibitor CGX0290, (C) CGX0290 + palmitoleate, or (D) CGX0290 + oleate. All cells received medium with $50 \%\left[\mathrm{U}^{13} \mathrm{C}\right]$-glucose. Cells were harvested on day 7 for studies of fatty acid metabolism, tricarboxylic acid (TCA) cycle activities, and deoxyribose synthesis. CGX0290 decreased fatty acid desaturation, glucose utilization for fatty acid synthesis (acetyl-CoA enrichment), and de novo synthesis. CGX0290 treatment also led to decreased cell density through increased cell death. Further analysis showed that deoxyribose new synthesis and oxidative pentose phosphate pathway activity were unchanged, while non-oxidative transketolase pathway activity was stimulated. Palmitoleate and oleate supplementation each partially ameliorated the effects of CGX0290. In 3T3-L1 cells, SCD1 promotes glucose utilization for fatty acid synthesis. In cell proliferation, SCD1 may promote cell survival, but does not impact the oxidative pathway of deoxyribose production. These effects may be mediated through the production of palmitoleate and oleate.
\end{abstract}

\section{Keywords}

Stearoyl-CoA desaturase enzyme 1; Glucose utilization; Cell proliferation; Lipogenesis; Stable isotopes; Pentose phosphate pathway

\footnotetext{
(C) Springer Science+Business Media New York 2013

Correspondence to: Jennifer K. Yee, jyee@labiomed.org.

Electronic supplementary material The online version of this article (doi:10.1007/s11306-013-0511-3) contains supplementary material, which is available to authorized users.
}

Conflict of interest The authors do not have financial conflicts of interest, and they have control of all primary data of this project. 


\section{Introduction}

Stearoyl-CoA desaturase enzyme 1 (SCD1) is a lipogenic enzyme that converts saturated fatty acids (SFA) to their corresponding monounsaturated fatty acids (MUFA). Its expression is often used as a biomarker of lipogenesis. SCD1 has been increasingly recognized for multiple roles in cellular metabolism. SCD1 is highly expressed in the liver and adipose tissue. The conversion of SFA palmitate (16:0) and stearate (18:0) to their respective MUFA, palmitoleate (16:1n-7) and oleate (18:1n-9), is essential to the initiation of triglyceride synthesis.

Upregulation of SCD1 was first recognized for its association with obesity and insulin resistance (Jeyakumar et al. 2009; Okada et al. 2005; Warensjo et al. 2006). In adipocyte development, SCD2 is constitutively expressed (Kaestner et al. 1989), while SCD1 is induced during differentiation, promoting lipogenesis for storage. In studies on SCD1 as a target for obesity intervention, SCD1 inhibition during 3T3-L1 adipocyte differentiation decreases fatty acid de novo synthesis (Collins et al. 2010). The SCD1 global knock-out mouse has a lean phenotype, is resistant to diet-induced obesity, and exhibits increased betaoxidation (Ntambi et al. 2002).

Recently, SCD1 has attracted additional interest as a potential molecular target for cancer treatment. In lung adenocarcinoma cells, SCD1 inhibition decreased the proportion of MUFA to SFA, increased programmed cell death, and interrupted cell cycle progression (Scaglia et al. 2009; Scaglia and Igal 2008). In prostate cancer cells, SCD1 inhibition also decreased lipogenesis, and prevented growth of xenograft tumors in mice (Fritz et al. 2010).

How SCD1 affects both lipogenesis and cell proliferation is unclear. This study aims to examine the role of glucose metabolism in relationship to SCD1. Glucose is a substrate for both production of deoxyribose in cell proliferation and fatty acids in de novo synthesis. Moreover, NADPH produced during deoxyribose synthesis in the oxidative phase of the pentose phosphate pathway can be used as reducing equivalents in fatty acid synthesis. Studies on glucose metabolism have presented varied findings from the effects of decreased SCD1 activity. The SCD1 adipose-tissue-specific knockout mouse demonstrates increased GLUT1 transporter expression, suggesting that SCD1 has an effect on glucose uptake. In contrast, lung adenocarcinoma cells that are treated with an SCD1 inhibitor do not restore cell proliferation when supplemented with high glucose (Scaglia et al. 2009), suggesting that SCD1 effects are independent of glucose supply.

We hypothesized that SCD1 affects multiple metabolic pathways through changes in glucose metabolism, and that SCD1 inhibition may decrease lipogenesis and cell proliferation through decreased glucose utilization. We tested the effects of an SCD1 inhibitor compound, CGX0290 (Yee et al. 2008) on 3T3-L1 preadipocytes during differentiation. Glucose utilization in fatty acid synthesis and deoxyribose synthesis were determined using $\left[\mathrm{U}^{13} \mathrm{C}\right]$-glucose as a stable isotope tracer. Our main objective was to determine the effects of SCD1 inhibition on glucose utilization during de novo fatty acid synthesis and deoxyribose production. In addition, since palmitoleate and oleate are produced by the 16-carbon and 18-carbon SCD1 pathways, respectively, we determined the potential restorative effects of palmitoleate or oleate supplementation during inhibition.

\section{Materials and methods}

\subsection{Compounds}

The action of SCD inhibitor CGX0290 (CompleGen, Inc) has been described previously (Yee et al. 2008). The $\mathrm{IC}_{50}$ for CGX0290 was $1.52 \mu \mathrm{M}$ by biochemical assay and $0.58 \mu \mathrm{M}$ 
by cell assay. CGX0290 was dissolved in dimethyl sulfoxide (DMSO) for use in the experiment.

$\left[\mathrm{U}^{13} \mathrm{C}\right]$-glucose and $\left[\mathrm{U}^{13} \mathrm{C}\right]$-stearate were purchased from Cambridge Laboratories, Inc. Palmitoleate and oleate were purchased from Matreya, LLC.

\subsection{Cell culture}

3T3-L1 cells were obtained from American Type Culture Collection (ATCC) and grown in $150 \mathrm{~cm}^{3}$ flasks at $37^{\circ} \mathrm{C}$ with $5 \% \mathrm{CO}_{2}$. All flasks were seeded with the same number of cells and grown to $100 \%$ confluence in high glucose Dulbecco's modified eagle medium (DMEM), $10 \%$ fetal bovine serum (FBS), and $1 \%$ antibiotics/ antimycotics. Two days after confluence, all flasks underwent differentiation induction by addition of dexamethasone 390 $\mathrm{ng} / \mathrm{mL}$, methylisobutylxanthine $115 \mu \mathrm{g} / \mathrm{mL}$, and insulin $10 \mu \mathrm{M}$ (MDI) (Kim et al. 2000). Flasks were assigned to one of 4 experimental groups for further treatment (Fig. 1; Table 1). The four groups were: control (group A), SCD1 inhibitor CGX0290 (group B), CGX0290 with palmitoleate supplementation $(0.05 \mathrm{mM}$ ) (group C), and CGX0290 with oleate supplementation $(0.05 \mathrm{mM}$ ) (Group D). DMSO was used as a placebo in group A. The main objective of the study was to determine the effects of SCD1 inhibition on glucose utilization, and therefore group A controlled for presence of SCD1 inhibitor. On days 0-3, the glucose composition of each treatment medium was $50 \%$ unlabeled glucose and $50 \%\left[\mathrm{U}^{13} \mathrm{C}\right]-$ glucose as a stable isotope tracer. On days 4-6 of the experiment, all flasks received standard high glucose medium with unlabeled glucose and no compounds. On days 5 and 6 , $\left[\mathrm{U}^{13} \mathrm{C}\right]$-stearate $(0.05 \mathrm{mM})$ was added to the culture medium as the only isotope. Medium was changed daily, and old medium was collected for analysis. Use of the stable isotopes $\left[\mathrm{U}^{13} \mathrm{C}\right]$-glucose and $\left[\mathrm{U}^{13} \mathrm{C}\right]$-stearate in sequential order allowed the separate determination of SCD1 activity during the 4 treatment days versus the last 3 days in the absence of SCD1 inhibitor. On day 7, cells were counted, and harvested for analysis of fatty acids, deoxyribose, and RNA. For determination of de novo synthesis, acetyl-CoA enrichment, and TCA cycle activities over 7 days, cell cultures were established as above, but with addition of $\left[\mathrm{U}^{13} \mathrm{C}\right]$-glucose as the only stable isotope tracer throughout 7 days.

\subsection{Fatty acid extraction and gas chromatography/mass spectrometry (GC/MS) analysis}

The previously published method of (Lowenstein et al. 1975) was used to extract total fatty acids, including those from triglycerides, phospholipids, and free fatty acids. Briefly, cells were saponified with $30 \% \mathrm{KOH}(\mathrm{w} / \mathrm{v})$ and 200-proof ethanol in a 1:1 ratio overnight at 70 ${ }^{\circ} \mathrm{C}$. The saponified mixture was acidified with $\mathrm{HCl}$ to a $\mathrm{pH}$ of 1 , extracted three times with petroleum ether, then air dried at room temperature. Fatty acids were derivatized as their methyl esters using $0.5 \mathrm{~N}$ methanolic $\mathrm{HCl}$, and dried under a nitrogen stream.

A Hewlett-Packard model 5973 selective mass detector coupled to a model $6890 \mathrm{GC}$ was used. Palmitate, palmitoleate, stearate, oleate, and vaccenate were separated on the GC with a Bpx70 column $(30 \mathrm{~m} \times 250 \mu \mathrm{m}$ ID $\times 0.25 \mu \mathrm{m}$ film thickness, SGE, Inc. Austin, TX) with the following conditions: helium flow rate, $1 \mathrm{~mL} / \mathrm{min}$; initial oven temperature, $150{ }^{\circ} \mathrm{C}$, with increase at $3{ }^{\circ} \mathrm{C} / \mathrm{min}$ to a final temperature of $221{ }^{\circ} \mathrm{C}$. The expected retention times for palmitate, palmitoleate, stearate, and oleate, were: 5.9, 6.5, 8.6, and $9.2 \mathrm{~min}$, respectively. Mass spectra of fatty acids were acquired using electron impact ionization in selective ion monitoring mode. Ion clusters monitored for the quantitation of isotopomers of palmitate were $\mathrm{m} / \mathrm{z} 269-276$ and $286-290$ with $\mathrm{m}+0$ at $\mathrm{m} / \mathrm{z} 270$ and $\mathrm{m}+16$ at $\mathrm{m} / \mathrm{z} 286$. The clusters corresponding to palmitoleate were $\mathrm{m} / \mathrm{z} 236-240$ and $251-255$; for stearate, $\mathrm{m} / \mathrm{z} 298-302$ with $\mathrm{m}+0$ at $\mathrm{m} / \mathrm{z} 298$, and $\mathrm{m} / \mathrm{z}$ 312-316 with $\mathrm{m}+18$ at $\mathrm{m} / \mathrm{z} 316$; for oleate, $\mathrm{m} / \mathrm{z}$ 264-267, and $\mathrm{m}+18$ at $\mathrm{m} / \mathrm{z} 314$. 


\subsection{Fatty acid spectral data analysis}

Distribution of the mass isotopomers was determined from the spectral data using a previously published method (Lee et al. 1991) that corrects for the contribution of derivatizing agent and ${ }^{13} \mathrm{C}$ natural abundance to the mass isotopomer distribution of the compound of interest. The isotopomer peaks within a cluster for each compound of interest were monitored. The resulting mass isotopomer distribution was expressed in molar fractions $(\mathrm{m} 0, \mathrm{~m} 1, \mathrm{~m} 2, \mathrm{~m} 3$, etc.) corresponding to the fraction of molecules that contain 0,1 , $2,3, \ldots . .{ }^{13} \mathrm{C}$ substitutions after corrections for the natural abundance of ${ }^{13} \mathrm{C}$. Use of the stable isotopes $\left[\mathrm{U}^{13} \mathrm{C}\right]$-glucose and $\left[\mathrm{U}^{13} \mathrm{C}\right]$-stearate allowed the separation of three distinct fatty acid pools: exogenous fatty acids as represented by the $\left[\mathrm{U}^{13} \mathrm{C}\right]$-stearate $(\mathrm{m}+18)$, the newly synthesized fatty acids as represented by the mass-shifted $m+2$ and $m+4$ fatty acids, and the preexisting unlabeled $(\mathrm{m}+0)$ fatty acids. These values were used for the calculation of desaturation indices and de novo lipogenesis.

\subsection{The desaturation indices}

Total and isotopic desaturation indices were determined. First, the ratios of total palmitoleate/palmitate (16:1/16:0), and oleate/stearate (18:1n-9/18:0) were determined from the ion chromatogram, reflecting the total balance between production and clearance of these fatty acids.

Secondly, the isotopic ${ }^{13} \mathrm{C}$-palmitoleate/palmitate and ${ }^{13} \mathrm{C}$-oleate/stearate indices were determined to reflect the conversion rate during the SCD1 inhibitor treatment period, based on isotopomers that incorporated ${ }^{13} \mathrm{C}$ from $\left[\mathrm{U}^{13} \mathrm{C}\right]$-glucose. The isotopic indices were calculated by dividing the summation of molar fractions for each product by the summation of molar fractions for each precursor fatty acid $\left(\Sigma_{\mathrm{mn}}\right.$ product $/ \Sigma_{\mathrm{mn}}$ precursor $)$.

Lastly, the $m+18$ oleate $/ m+18$ stearate index was determined to reflect the conversion rate of $\left\{\mathrm{U}^{13} \mathrm{C}\right\}$-stearate during the later part of the experiment, after the inhibitor treatment was over. This ratio was determined by the peak height ratio of $m+18$ oleate $/ m+18$ stearate. (The $\mathrm{m}+16$ palmitate formed by chain shortening did not undergo desaturation to produce a significant peak of $m+16$ palmitoleate, so the $m+16$ palmitoleate $/ m+16$ palmitate ratio was not determined.)

\subsection{Acetyl-CoA enrichment and de novo synthesis}

To assess fatty acid synthesis, we monitored the incorporation of ${ }^{13} \mathrm{C}$ isotope from $\left[\mathrm{U}^{13} \mathrm{C}\right]-$ glucose into fatty acids. $\mathrm{m}+2, \mathrm{~m}+4$, and $\mathrm{m}+6$, etc., isotopomers result from $\left[\mathrm{U}^{13} \mathrm{C}\right]$ glucose incorporation into palmitate or stearate in de novo lipogenesis. Precursor acetylCoA enrichment was calculated from the consecutive mass isotopomer ratio $m+4 / m+2$. De novo synthesis over 7 days was then calculated using the acetyl-CoA enrichment (Lee et al. 1992).

\subsection{Glucose consumption}

Glucose concentration of cell culture medium was determined with the Glucose HK Assay Kit (Sigma). Glucose content of the volume of each flask was calculated. Glucose consumption from the medium was then calculated indirectly by subtracting the glucose content of the post-treatment medium from that of the pretreatment medium.

\subsection{Tricarboxylic acid (TCA) cycle activity}

TCA cycle activity related to glucose utilization for fatty acid synthesis was studied using mass isotopomers of glutamate. The incorporation of ${ }^{13} \mathrm{C}$ from $\left[\mathrm{U}^{13} \mathrm{C}\right]$-glucose typically 
labels carbons 2 and $3(\mathrm{C} 2-\mathrm{C} 3)$ of glutamate via the pyruvate carboxylase (PC) pathway, and carbons 4 and $5(\mathrm{C} 4-\mathrm{C} 5)$ of glutamate via the pyruvate dehydrogenase (PDH) pathways.

Glutamate was extracted from cell culture medium by column chromatography using a Dowex-1 anion exchange column and acetic acid elution (Lee et al. 1996). Glutamate was derivatized as its $n$-trifluoroacetyl- $n$-butylester and analyzed by GC/MS. Fragment m/z 152 represents the $\mathrm{C} 2-\mathrm{C} 4$ enriched fragment (pyruvate carboxylase), and fragment $\mathrm{m} / \mathrm{z} 198$ represents the $\mathrm{C} 2-\mathrm{C} 5$ enriched fragment (pyruvate carboxylase + pyruvate dehydrogenase). The pyruvate carboxylase/pyruvate dehydrogenase (PC/PDH) ratio was thus determined as: ( $\mathrm{m} 2$ of $\mathrm{m} / \mathrm{z} 152$ fragment $) /[(\mathrm{m} 2$ of $\mathrm{m} / \mathrm{z} 198$ fragment $)-(\mathrm{m} 2$ of $\mathrm{m} / \mathrm{z} 152$ fragment $)]$ to evaluate for differences in pyruvate entrance into the TCA cycle for acetyl-CoA production.

\subsection{Cell density determination}

Cell counting was carried out on day 7. Harvested cell pellets were resuspended in a uniform volume of phosphate buffered saline. An aliquot from each suspension was stained with trypan blue. Adipocytes were then counted on two grids per sample using a hemocytometer.

\subsection{Pentose cycle activity}

Stable isotope enrichment in deoxyribose of DNA was used to monitor preadipocyte cell division, which occurs primarily during early differentiation (Tang and Lane 2012). DNA was isolated using Tri-Reagent (Sigma Aldrich) based on a previously published method (Chomczynski and Sacchi 1987). DNA was quantified by spectrophotometry at a wavelength of $260 \mathrm{~nm}$. The DNA pellet was dissolved in HPLC water and enzyme digested into deoxynucleotides (Chen and Abramson 1998). Deoxyadenosine was isolated using LC18 SPE (Supelco) (Neese et al. 2001), air dried, and converted into aldonitrile per-acetate derivatives using hydroxyl amine and acetic anhydride. The GC was equipped with a Phenomenex Zebron-5 capillary column ( $30.0 \mathrm{~m} \times 0.25 \mathrm{~mm}$ ID, $0.25 \mu \mathrm{m}$ film thickness) with the following settings: injector temperature $250{ }^{\circ} \mathrm{C}$ with flow rate of $1 \mathrm{~mL} / \mathrm{min}$ of helium as carrier gas. The column temperature was initially at $180{ }^{\circ} \mathrm{C}$ then increased by 5 ${ }^{\circ} \mathrm{C} / \mathrm{min}$ to $220{ }^{\circ} \mathrm{C}$, then increased again by $100{ }^{\circ} \mathrm{C} / \mathrm{min}$ to reach a final temperature of 300 ${ }^{\circ} \mathrm{C}$. Mass spectra were obtained through chemical ionization and data recorded for mass isotopomers of deoxyribose at $\mathrm{m} / \mathrm{z}$ 197-204 (Centelles et al. 2007). The unlabeled fraction $(1-\mathrm{m} 0)$ represents the newly synthesized deoxyribose. The $\mathrm{m} 5 / \Sigma \mathrm{m}$ enrichment ratio represents deoxyribose produced through the oxidative glucose-6-phosphate dehydrogenase (G6PDH) pathway, while the $\mathrm{m} 3 / \Sigma \mathrm{m}$ enrichment ratio represents deoxyribose produced through the non-oxidative transketolase (TK) pathway.

\subsection{Statistical analysis}

Statistical analyses were performed using SigmaStat 11.0 and SYSTAT software. Data sets were examined for normality in distribution and equality of variance. Data were analyzed using one-way analysis of variance (ANOVA), followed by the Dunnett's test in paired comparisons against control group A. For the real-time PCR data (Supplemental Data), pairwise comparisons were made by $t$ tests due to unequal variance between groups.

\section{Results}

\subsection{Desaturation indices}

Both the palmitoleate/palmitate and oleate/stearate indices were decreased with addition of CGX0290 in group B (Table 2a, $p<0.001$ ). Palmitoleate (group C) supplementation restored both the palmitoleate/palmitate and oleate/ stearate indices. Oleate supplementation (group D) also restored the palmitoleate/palmitate index, but caused a significant increase in the oleate/stearate index in comparison to the control. 
The isotopic desaturation indices represent the desaturation of the fatty acids made de novo from the $\left[\mathrm{U}^{13} \mathrm{C}\right]$-glucose (Table $2 \mathrm{~b}$ ) during the intervention period. Both ${ }^{13} \mathrm{C}$-palmitoleate/ palmitate and ${ }^{13} \mathrm{C}$-oleate/stearate indices were decreased by CGX0290 treatment ( $\sim 67$ and $\sim 75 \%$ of control values, respectively). Only partial recovery occurred with palmitoleate supplementation (palmitoleate $\sim 79$, oleate $\sim 90 \%$ of control). In contrast, with oleate supplementation, the ${ }^{13} \mathrm{C}$-palmitoleate/palmitate index partially recovered to $78 \%$ of control values, but the ${ }^{13} \mathrm{C}$-oleate/stearate index was further decreased ( $57 \%$ of control values).

The $m+18$ oleate $/ m+18$ stearate index represents desaturation during the post-inhibitor treatment period. An increase in this index occurred after CGX0290 treatment was stopped (Table 2b). However, desaturation remained similar to controls with palmitoleate supplementation, while oleate supplementation suppressed it.

\subsection{Glucose consumption}

Glucose consumption was unchanged in the CGX0290 treated group B $\left(5.9 \pm 0.5 \times 10^{-2}\right.$ $\mathrm{mmol} / 10^{6}$ cells) compared with controls $\left(5.5 \pm 0.3 \times 10^{-2} \mathrm{mmol} / 10^{6}\right.$ cells) (Table 3 ). Glucose consumption was increased in cells receiving palmitoleate $\left(8.7 \pm 1.3 \times 10^{-2} \mathrm{mmol} /\right.$ $10^{6}$ cells $)$ or oleate $\left(11.1 \pm 1.1 \times 10^{-2} \mathrm{mmol} / 10^{6}\right.$ cells $)$ supplementation.

\subsection{Acetyl-CoA enrichment and de novo synthesis}

Acetyl-CoA enrichment represents $\left[\mathrm{U}^{13} \mathrm{C}\right]$-glucose utilization for fatty acid synthesis. CGX0290 treatment in group B led to a decrease in the acetyl-CoA enrichment of palmitate (Table 3). Palmitoleate supplementation did not restore this low level, while addition of oleate restored it to the level of controls.

De novo synthesis, represented by the FNS palmitate over 7 days, followed the same pattern as acetyl-CoA enrichment (Table 3). The FNS palmitate was decreased in the CGX0290 treatment group compared with control. Supplementation with oleate, but not palmitoleate, restored the FNS to the same level as the control.

\subsection{TCA cycle activity}

Glutamate enrichment was analyzed to determine the labeling of $\mathrm{C} 2-\mathrm{C} 3$ versus $\mathrm{C} 4-\mathrm{C} 5$ positions. The $\mathrm{PC} / \mathrm{PDH}$ ratio represents the relative contribution of the pyruvate carboxylase (PC) and pyruvate dehydrogenase (PDH) pathways to TCA cycle flux. PDH action on pyruvate is the source of acetyl-CoA for fatty acid synthesis. Despite the decreases in acetylCoA enrichment and FNS palmitate with CGX0290 treatment in group B, the PC/PDH ratio was significantly decreased (Table 3), suggesting that the activity of PDH was less suppressed than that of PC. The levels increased back to the level of controls with palmitoleate or oleate supplementation.

\subsection{Cell proliferation}

The final cell density was decreased after treatment with CGX0290 (Table 4). Palmitoleate supplementation restored the cell density to control levels, while oleate did not. The deoxyribose new synthesis rate was unaffected by CGX0290 treatment, while palmitoleate and oleate supplementation stimulated higher levels. The fractions of new deoxyribose synthesis based on $50 \%\left[\mathrm{U}^{13} \mathrm{C}\right]$-glucose exposure over 4 days correspond to cell division rates of about $50-60 \%$ in the groups. The $\mathrm{m} 5 / \Sigma \mathrm{m}$ ratio, which reflects oxidative G6PDH activity, was unchanged except for a decrease with palmitoleate. The enrichment ratio $\mathrm{m} 3 /$ $\Sigma \mathrm{m}$, which reflects non-oxidative transketolase activity, was stimulated with CGX0290 treatment. The $\mathrm{m} 3 / \mathrm{\Sigma m}$ ratio decreased with palmitoleate supplementation, but increased with oleate supplementation. TK activity overall contributed to $22.6-25.9 \%$ of the new synthesis. 


\section{Discussion}

The process of preadipocyte differentiation involves both cell proliferation and lipogenesis. SCD1 is an essential step in lipid accumulation since MUFA are preferentially incorporated into triglycerides for storage. The present study was conducted to investigate how SCD1 affects glucose utilization in pathways of lipogenesis and cell proliferation in adipocytes. We demonstrated that SCD1 inhibition decreased glucose utilization for fatty acid synthesis and decreased cell density, but did not affect overall deoxyribose synthesis or oxidative pentose phosphate pathway activity.

The SCD1 inhibitor CGX0290 was previously shown to be effective in decreasing desaturation in HepG2 cells (Yee et al. 2008). Since other studies have raised concerns about potential harmful effects from SCD1 inhibition (Brown and Rudel 2010), this study tested a short-term 4-day treatment with CGX0290 when cell proliferation is active during differentiation. At the end of 7 days, CGX0290 had effectively inhibited SCD1 activity and decreased total desaturation in both the palmitoleate/palmitate and the oleate/stearate ratios. However, the desaturation indices are influenced by rates of both MUFA production and disappearance. By examining stable isotope incorporation and distribution, we were able to distinguish between the newly made fatty acids and preexisting ones. Desaturation of newly synthesized fatty acids made from $\left[\mathrm{U}^{13} \mathrm{C}\right]$-glucose supplied during the treatments was shown to be decreased. In contrast, despite a trend toward decreased SCD1 gene expression, the $m+18$ oleate $/ m+18$ stearate ratio was increased after CGX0290 was withdrawn, suggesting a recovery in desaturase activity after the inhibitor treatment was terminated. This would be consistent with our previous suggestion that CGX0290 is a reversible competitive enzyme inhibitor (Yee et al. 2008), exerting mainly post-transcriptional effects. Alternatively, it is possible that CGX0290 caused SCD2 inhibition, which is known to cause decreased SCD1 and PPARY expression in turn (Christianson et al. 2008).

In the studies related to glucose utilization for fatty acid synthesis, glucose consumption adjusted for cell count was similar to controls after treatment with CGX0290. In contrast, a study on 3T3-L1 cells with another SCD1 inhibitor, 4-(2-chlorophenoxy)- $\mathrm{N}$-(3(methylcarbamoyl)-phenyl)piperidine-1-carboxamide (Hyun et al. 2010), demonstrated increased glucose uptake accompanied by increased GLUT1 expression. More studies are needed to determine whether lack of an effect by CGX0290 on glucose consumption is a compound-specific effect, or related to other experimental factors.

The measurement of fractional new synthesis (FNS) of palmitate showed that SCD1 inhibition decreased de novo synthesis (see also Supplemental Data for lipogenic gene expression). Decreased de novo synthesis is consistent with findings from studies on SCD1 inhibition in adipocytes (Collins et al. 2010) and lung adenocarcinoma (Scaglia and Igal 2008). The block in SCD1 activity leads to accumulation of saturated fatty acids, which inhibit acetyl-CoA carboxylase 1 (ACC1), and subsequently decreases de novo synthesis.

The acetyl-CoA enrichment, which reflects glucose utilization for fatty acid synthesis, also decreased with SCD1 inhibition despite a lack of change in medium glucose consumption. Therefore, we examined TCA cycle activities to determine whether changes in the balance between PC (pyruvate carboxylase) and PDH (pyruvate dehydrogenase) activities occurred. An increase in the PC/ PDH ratio suggests an increase in PC production of oxaloacetate to be used toward gluconeogenesis, while a decrease suggests increase in PDH activity toward fatty acid synthesis. Our data showed that the PC/PDH ratio decreased with SCD1 inhibition, favoring increased lipogenesis. In the context of low acetyl CoA enrichment, however, the decreased PC/PDH ratio indicates a shift in substrate utilization from glucose 
to other unlabeled sources, which may include preexisting fatty acids or amino acids from FBS in the culture medium.

SCD1 inhibition impacted cell proliferation by decreasing the final adipocyte cell density. Consistent with findings from other SCD1 inhibition studies (Hess et al. 2010), the decrease in cell density was attributable to apoptosis (see Supplemental Data). The unchanged deoxyribose synthesis rate among the 3T3-L1 cells treated with CGX0290 indicated maintenance of cell division. Information regarding the contribution of glucose to deoxyribose synthesis through the pentose phosphate pathway was revealed by examination of mass isotopomer enrichment. The oxidative G6PDH activity reflected by the $\mathrm{m} 5 / \mathrm{\Sigma m}$ ratio was unchanged despite SCD1 inhibition, indicating that glucose utilization for DNA synthesis during cell proliferation was maintained. On the other hand, SCD1 inhibition stimulated the non-oxidative transketolase pathway, which may be a response to increased cell death. Therefore, our study demonstrated evidence of compromised glucose utilization in lipogenesis, but not in deoxyribose production. However, both processes showed evidence of a shift toward the use of non-glucose substrates.

Addition of MUFAs during SCD1 inhibition demonstrated different responses to palmitoleate and oleate. Their divergent effects on the total and isotopic desaturation indices support differences in regulation of the 16-carbon versus 18-carbon pathways. With regards to glucose utilization in lipogenesis, both palmitoleate and oleate addition led to increased glucose consumption. Oleate was more effective in restoring acetyl-CoA enrichment and de novo synthesis, although TCA cycle activity returned to control levels under both treatments. In cell proliferation, palmitoleate or oleate added during SCD1 inhibition appeared to improve cell numbers, indicating that MUFA promotes cell survival. (CGX0290 itself, therefore, is unlikely to be cytotoxic). However, palmitoleate alone maintained normal cell counts. Despite increased deoxyribose synthesis with palmitoleate, both G6PDH and transketolase activities were decreased, implying some increased efficiency conferred by palmitoleate. Oleate only modestly increased cell counts despite increased deoxyribose new synthesis and transketolase activity. In biological systems, levels of palmitoleate are naturally low compared to oleate, and our experiment is limited in that we used identical medium concentrations of either fatty acid. Overall, more studies are needed to determine the individual roles that palmitoleate and oleate have.

CGX0290 clearly decreases lipogenesis and cell proliferation. SCD1 inhibitors such as this one may be further investigated for anti-adipogenic properties. These studies should proceed with caution knowing that saturated fatty acid accumulation may be cytotoxic to cells and cause lipoapoptosis (Igal 2010). In addition, SCD1 deficiency in mice is also associated with increased inflammation and atherosclerosis (MacDonald et al. 2009). However, our shortterm inhibitor treatment during a brief early period still produced a final phenotype of decreased lipogenesis and cell proliferation. Longer-term studies may be done to determine the lasting effects of SCD1 inhibition. The possibility of short-term treatment by SCD1 inhibition during critical periods of adipose tissue development may be explored.

In conclusion, SCD1 promotes glucose utilization for fatty acid de novo synthesis, and promotes cell survival without effects on the oxidative pathway of deoxyribose synthesis. The pathways of lipogenesis and cell proliferation do not appear directly linked through glucose utilization. Further studies are needed to determine whether these pathways are interconnected through a wider metabolic network.

\section{Supplementary Material}

Refer to Web version on PubMed Central for supplementary material. 


\section{Acknowledgments}

We would like to thank John Swindle and Joel Hedgpeth for CompleGen, Inc's generous donation of CGX0290. We appreciate advice regarding 3T3-L1 cell culture from Utpal Pajvani, MD, PhD (Columbia University). Fatty acid composition was analyzed at the Biomedical Mass Spectrometry facility of the University of California Los Angeles Clinical and Translational Science Institute (UL1TR000124) at the Los Angeles Biomedical Research Institute (LABioMed) at Harbor-UCLA. We appreciate biostatistical advice from Peter Christenson, PhD, of LABioMed.

\section{References}

Brown JM, Rudel LL. Stearoyl-coenzyme A desaturase 1 inhibition and the metabolic syndrome: Considerations for future drug discovery. Current Opinion in Lipidology. 2010; 21(3):192-197. [PubMed: 20216310]

Centelles JJ, Ramos-Montoya AF, Lim SK, Bassilian S, Boros LG, Marin S, et al. Stable isotope tracer based quantitation and pathways of deoxyribose synthesis: Implications for de novo DNA synthesis and repair in HepG2 cells. Metabolomics. 2007; 3:105-112.

Chen P, Abramson FP. Measuring DNA synthesis rates with [1-13C]glycine. Analytical Chemistry. 1998; 70(9):1664-1669. [PubMed: 9599574]

Chomczynski P, Sacchi N. Single-step method of RNA isolation by acid guanidinium thiocyanatephenol-chloroform extraction. Analytical Biochemistry. 1987; 162(1):156-159. [PubMed: 2440339]

Christianson JL, Nicoloro S, Straubhaar J, Czech MP. Stearoyl-CoA desaturase 2 is required for peroxisome proliferator-activated receptor gamma expression and adipogenesis in cultured 3T3-L1 cells. Journal of Biological Chemistry. 2008; 283(5):2906-2916. [PubMed: 18032385]

Collins JM, Neville MJ, Hoppa MB, Frayn KN. De novo lipogenesis and stearoyl-CoA desaturase are coordinately regulated in the human adipocyte and protect against palmitate-induced cell injury. Journal of Biological Chemistry. 2010; 285(9):6044-6052. [PubMed: 20032470]

Fritz V, Benfodda Z, Rodier G, Henriquet C, Iborra F, Avances C, et al. Abrogation of de novo lipogenesis by stearoyl-CoA desaturase 1 inhibition interferes with oncogenic signaling and blocks prostate cancer progression in mice. Molecular Cancer Therapeutics. 2010; 9(6):1740-1754. [PubMed: 20530718]

Hess D, Chisholm JW, Igal RA. Inhibition of stearoyl-CoA desaturase activity blocks cell cycle progression and induces programmed cell death in lung cancer cells. PLoS ONE. 2010; 5(6):e11394. [PubMed: 20613975]

Hyun CK, Kim ED, Flowers MT, Liu X, Kim E, Strable M, et al. Adipose-specific deletion of stearoyl-CoA desaturase 1 up-regulates the glucose transporter GLUT1 in adipose tissue. Biochemical and Biophysical Research Communications. 2010; 399(4):480-486. [PubMed: 20655875]

Igal RA. Stearoyl-CoA desaturase-1: A novel key player in the mechanisms of cell proliferation, programmed cell death and transformation to cancer. Carcinogenesis. 2010; 31(9):1509-1515. [PubMed: 20595235]

Jeyakumar SM, Lopamudra P, Padmini S, Balakrishna N, Giridharan NV, Vajreswari A. Fatty acid desaturation index correlates with body mass and adiposity indices of obesity in Wistar NIN obese mutant rat strains WNIN/ Ob and WNIN/GR-Ob. Nutrition and Metabolism (London). 2009; 6:27.

Kaestner KH, Ntambi JM, Kelly TJ Jr, Lane MD. Differentiation-induced gene expression in 3T3-L1 preadipocytes. A second differentially expressed gene encoding stearoyl-CoA desaturase. Journal of Biological Chemistry. 1989; 264(25):14755-14761. [PubMed: 2570068]

Kim YC, Gomez FE, Fox BG, Ntambi JM. Differential regulation of the stearoyl-CoA desaturase genes by thiazolidinediones in 3T3-L1 adipocytes. Journal of Lipid Research. 2000; 41(8):13101316. [PubMed: 10946019]

Lee WN, Bergner EA, Guo ZK. Mass isotopomer pattern and precursor-product relationship. Biological Mass Spectrometry. 1992; 21(2):114-122. [PubMed: 1606182]

Lee WN, Byerley LO, Bergner EA, Edmond J. Mass isotopomer analysis: Theoretical and practical considerations. Biological Mass Spectrometry. 1991; 20(8):451-458. [PubMed: 1768701] 
Lee WN, Edmond J, Bassilian S, Morrow JW. Mass isotopomer study of glutamine oxidation and synthesis in primary culture of astrocytes. Developmental Neuroscience. 1996; 18(5-6):469-477. [PubMed: 8940620]

Lowenstein JM, Brunengraber H, Wadke M. Measurement of rates of lipogenesis with deuterated and tritiated water. Methods in Enzymology. 1975; 35:279-287. [PubMed: 1121283]

MacDonald ML, van Eck M, Hildebrand RB, Wong BW, Bissada N, Ruddle P, et al. Despite antiatherogenic metabolic characteristics, SCD1-deficient mice have increased inflammation and atherosclerosis. Arteriosclerosis, Thrombosis, and Vascular Biology. 2009; 29(3):341-347.

Neese RA, Siler SQ, Cesar D, Antelo F, Lee D, Misell L, et al. Advances in the stable isotope-mass spectrometric measurement of DNA synthesis and cell proliferation. Analytical Biochemistry. 2001; 298(2):189-195. [PubMed: 11700973]

Ntambi JM, Miyazaki M, Stoehr JP, Lan H, Kendziorski CM, Yandell BS, et al. Loss of stearoyl-CoA desaturase-1 function protects mice against adiposity. Proceedings of the National Academy of Science USA. 2002; 99(17):11482-11486.

Okada T, Furuhashi N, Kuromori Y, Miyashita M, Iwata F, Harada K. Plasma palmitoleic acid content and obesity in children. American Journal of Clinical Nutrition. 2005; 82(4):747-750. [PubMed: 16210702]

Scaglia N, Chisholm JW, Igal RA. Inhibition of stearoylCoA desaturase-1 inactivates acetyl-CoA carboxylase and impairs proliferation in cancer cells: Role of AMPK. PLoS ONE. 2009; 4(8):e6812. [PubMed: 19710915]

Scaglia N, Igal RA. Inhibition of stearoyl-CoA desaturase 1 expression in human lung adenocarcinoma cells impairs tumorigenesis. International Journal of Oncology. 2008; 33(4):839-850. [PubMed: 18813799]

Tang QQ, Lane MD. Adipogenesis: From stem cell to adipocyte. Annual Review of Biochemistry. 2012; 81:715-736.

Warensjo E, Ohrvall M, Vessby B. Fatty acid composition and estimated desaturase activities are associated with obesity and lifestyle variables in men and women. Nutrition Metabolism and Cardiovascular Disease. 2006; 16(2):128-136.

Yee JK, Mao CS, Hummel HS, Lim S, Sugano S, Rehan VK, et al. Compartmentalization of stearoylcoenzyme A desaturase 1 activity in HepG2 cells. Journal of Lipid Research. 2008; 49(10):21242134. [PubMed: 18599738] 


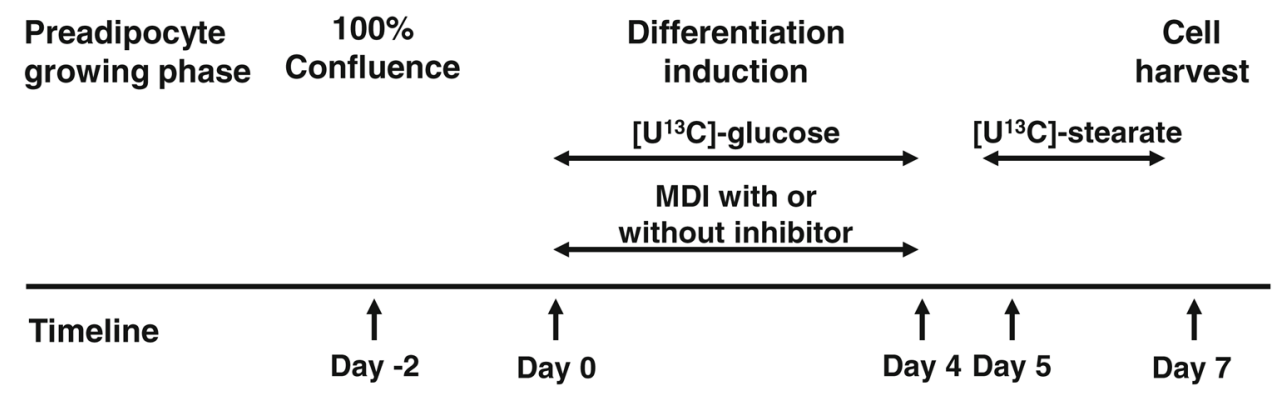

Fig. 1.

Timeline for the experiment and enrichment of medium with $\left[\mathrm{U}^{13} \mathrm{C}\right]$-glucose and $\left[\mathrm{U}^{13} \mathrm{C}\right]-$ stearate 


\section{Table 1}

Experimental treatment groups

\begin{tabular}{ll}
\hline Group & Cell culture medium \\
\hline A (control) & DMSO placebo \\
B & CGX0290 \\
C & CGX0290 + palmitoleate \\
D & CGX0290+ oleate \\
\hline
\end{tabular}

The four groups all received MDI differentiation compounds and the above treatments in the cell culture medium

MDI methylisobutylxanthine, dexamethasone, and insulin

SCD1 inhibitor CGX0290 in DMSO-10uM

Palmitoleate-0.05 $\mathrm{mM}$

Oleate- $-0.05 \mathrm{mM}$ 


\section{Table 2}

Total desaturation indices, isotopic indices from $\left[\mathrm{U}^{13} \mathrm{C}\right]$-glucose incorporation during the intervention period, and the $m+18$ oleate $/ m+18$ stearate index after the intervention

\begin{tabular}{|c|c|c|c|}
\hline & Palmitoleate/palmitate & Oleate/stearate & \\
\hline \multicolumn{4}{|c|}{ a. Total desaturation indices } \\
\hline A (control) & $0.72 \pm 0.03$ & $1.36 \pm 0.03$ & \\
\hline $\mathrm{B}$ & $0.37 \pm 0.02^{* *}$ & $0.89 \pm 0.04^{* *}$ & \\
\hline $\mathrm{C}$ & $0.74 \pm 0.02$ & $1.29 \pm 0.11$ & \\
\hline \multirow[t]{2}{*}{$\mathrm{D}$} & $0.77 \pm 0.01$ & $1.84 \pm 0.10^{* *}$ & \\
\hline & ${ }^{13} \mathrm{C}$-Palmitoleate/palmitat & ${ }^{13} \mathrm{C}$-oleate/stearate & $m+18$ oleate $/ m+18$ stearate \\
\hline \multicolumn{4}{|c|}{ b. Isotopic desaturation indices } \\
\hline A (control) & $1.18 \pm 0.03$ & $0.81 \pm 0.01$ & $0.0633 \pm 0.0004$ \\
\hline $\mathrm{B}$ & $0.79 \pm 0.01^{* *}$ & $0.61 \pm 0.01^{* *}$ & $0.076 \pm 0.001^{* *}$ \\
\hline $\mathrm{C}$ & $0.93 \pm 0.02^{* *}$ & $0.73 \pm 0.01^{* *}$ & $0.061 \pm 0.001$ \\
\hline $\mathrm{D}$ & $0.93 \pm 0.01^{* *}$ & $0.46 \pm 0.02^{* *}$ & $0.060 \pm 0.001^{*}$ \\
\hline
\end{tabular}


Table 3

Glucose consumption, acetyl-CoA enrichment, de novo synthesis of palmitate, and TCA cycle activity

\begin{tabular}{|c|c|c|c|c|}
\hline Group & Glucose consumption & Fatty acid synthesis & & TCA Cycle Activity \\
\hline & $\left(\times 10^{-2} \mathrm{mmol} / 10^{6}\right.$ cells $)$ & Acetyl-CoA enrichment $(\%)$ & $\begin{array}{l}\text { De Novo synthesis (\%FNS palmitate over } 7 \\
\text { days) }\end{array}$ & PC/PDH (at 7 days) \\
\hline A (control) & $5.5 \pm 0.3$ & $19.5 \pm 0.2$ & $67.1 \pm 0.5$ & $1.53 \pm 0.02$ \\
\hline B & $5.9 \pm 0.5$ & $17.8 \pm 0.1^{* * *}$ & $55.6 \pm 2.7^{*}$ & $1.18 \pm 0.01^{* *}$ \\
\hline $\mathrm{C}$ & $8.7 \pm 1.3^{*}$ & $18.4 \pm 0.3^{* *}$ & $55.4 \pm 4.8^{*}$ & $1.44 \pm 0.05$ \\
\hline $\mathrm{D}$ & $11.1 \pm 1.1^{*}$ & $19.0 \pm 0.1$ & $69.2 \pm 3.6$ & $1.47 \pm 0.02$ \\
\hline
\end{tabular}

Data are presented as the mean \pm SEM

* Significantly different when compared with control, $p<0.05$

*** Significantly different compared with control, $p<0.01$ 
Table 4

Cell proliferation data

\begin{tabular}{|c|c|c|c|c|}
\hline Group & $\begin{array}{l}\text { Cell density }\left(\times 10^{6} \text { cells } /\right. \\
\text { mL })\end{array}$ & $\begin{array}{l}\text { Deoxyribose new synthesis } \\
(1-\mathrm{m} 0)^{a}\end{array}$ & $\begin{array}{l}\text { m5/ } \\
\neq 0)\end{array}$ & $\underset{(m \neq 0)}{m 3 / \Sigma m}$ transketolase activity \\
\hline A (control) & $2.34 \pm 0.06$ & $0.258 \pm 0.010$ & $0.302 \pm 0.008$ & $0.244 \pm 0.005$ \\
\hline B & $1.31 \pm 0.10^{* *}$ & $0.269 \pm 0.002$ & $0.315 \pm 0.001$ & $0.259 \pm 0.001^{*}$ \\
\hline $\mathrm{C}$ & $1.98 \pm 0.24$ & $0.307 \pm 0.013 *$ & $0.274 \pm 0.009^{*}$ & $0.226 \pm 0.000 * *$ \\
\hline $\mathrm{D}$ & $1.65 \pm 0.17^{*}$ & $0.329 \pm 0.003^{*}$ & $0.310 \pm 0.001$ & $0.258 \pm 0.001 *$ \\
\hline
\end{tabular}

Data are presented as the mean \pm SEM

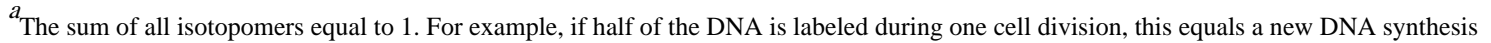
fraction of 0.5

* Significantly different when compared with control A, $p<0.05$

*** Significantly different when compared with control A, $p<0.01$ 